\title{
VARIACIÓN LÉXICA GEOLECTAL, LEGISLACIÓN SECTORIAL Y ESTANDARIZACIÓN: LAS DENOMINACIONES DE LOS ESTABLECIMIENTOS DE ALOJAMIENTO TURÍSTICO EN EL ESPAÑOL DE AMÉRICA*
}

\section{DIALECTAL LEXICAL VARIATION, SECTORAL LEGISLATION AND STANDARDIZATION: THE NAMES OF HOSPITALITY ESTABLISHMENTS IN AMERICAN SPANISH}

\author{
Julia Sanmartín SÁez \\ Universitat de València
}

Recibido: 27/01/2016

Aceptado: 21/04/2016

\begin{abstract}
Resumen
Esta investigación tiene como objetivo general caracterizar la diversidad de denominaciones de los establecimientos de alojamiento turístico en Argentina, Chile y Costa Rica desde un enfoque poliédrico: desde la regulación legal, desde el uso en textos divulgativos y desde su sanción en el diccionario. El primer enfoque u objetivo específico pretende describir qué denominaciones se documentan en los textos legales reguladores del sector turístico y en las normas de estandarización lingüística de estos tres países. El segundo enfoque coteja las denominaciones reguladas con su uso real en páginas web comerciales y en recursos institucionales, y analiza las estrategias pragmalingüísticas que subyacen a este uso. En el tercer enfoque se examina si estas denominaciones ya se han registrado en los diccionarios académicos y si las
\end{abstract}

\begin{abstract}
The general objective in this research is to characterize the diversity of names of tourist accommodations in Argentina, Chile and Costa Rica from a multiple focus: from the legal regulation, from the usage in popular texts and from its acceptance in dictionaries. The first focus or specific objective attempts to describe which names are documented in the legal texts that regulate the tourism industry and in the linguistic standardization norms of these three countries. The second focus contrasts the regulated names with their real usage found in commercial webpages and in institutional resources, and analyzes the pragmalinguistic strategies that underlie this usage. As for the third focus, it is examined whether these names have been registered in the academic dictionaries and whether their lexicographic
\end{abstract}

\footnotetext{
* Publicación del Proyecto de investigación concedido por el Ministerio de Economía y Competitividad. Referencia FFI2011-24712, Análisis léxico y discursivo de corpus paralelos y comparables (español, inglés y francés) de páginas electrónicas de promoción turística. 2011-2014.
}

Para citar este artículo / To cite this article: Sanmartín Sáez, Julia (2016). Variación léxica geolectal, legislación sectorial y estandarización: las denominaciones de los establecimientos de alojamiento turístico en el español de América. ELUA, 30: 257-274. doi:10.14198/ELUA2016.30.12 
definiciones lexicográficas incorporan de algún modo las definiciones más técnicas halladas en los textos legales.

PALABRAS CLAVE: terminología, variación léxica geolectal, estandarización, estrategia pragmalingüística, discurso turístico. definitions incorporate somehow the more technical definitions found in the legal texts.

KEYWORDS: terminology, dialectal lexical variation, standardization, pragmalinguistic strategy, tourism discourse.

\section{Marco teórico: la variación terminológica desde una perspectiva comunicativa y panhispánica}

La cuestión que se aborda en este artículo es cómo se combinan la regulación sectorial y la estandarización lingüística de los términos con la variación geolectal de las lenguas, en sintonía con lo propuesto por Lebsanft et alii (2012) sobre variedades y normas, o en lo apuntado por Freixa et alii (2002), al considerar que la descripción de los fenómenos de variación debería preceder a la labor de uniformización.

Además de una variación geolectal, los términos pueden poseer una mayor o menor complejidad conceptual en función del ámbito del saber y caracterizarse también por un mayor o menor proceso de divulgación entre amplios sectores de la población, tal y como se ha constatado desde una perspectiva comunicativa de la Terminología como disciplina (Cabré, 1999). De hecho, este estudio se basa en la descripción contrastiva de los términos referidos a la tipología de establecimientos de alojamiento turístico en dos tipos de discursos y contextos comunicativos: en legislación sectorial y normas de estandarización, considerados como representantes de una comunicación especializada ${ }^{1}$, y en páginas web comerciales que ofertan y promocionan alojamientos para un receptor lego en la materia y, por consiguiente, se concebirían como discursos no especializados. Se parte de una noción gradual de especialidad (Cabré, 1999) y de una teoría lexicológica vertical (Ciapuscio, 2006). Y en ese recorrido vertical de divulgación de lo especializado, el diccionario académico aparece como una etapa última del proceso. De este modo, algunos términos acaban integrados en la lengua general (Calvi, 2006a; Contreras, 2008; Sánchez Manzanares, 2013).

Además de considerar el tipo de discurso y sus coordenadas enunciativas como causas de variación (Calvi, 2006a; Freixa, 2006; Condamines, 2010; Sanmartín, 2012; Seghezzi, 2013), la investigación asume que los términos son unidades formales, con una variación denominativa o sinonimia (Regueiro, 2010; Estornell, 2013; Fernández Silva, 2013) y unidades cognitivas, con una variación conceptual (Temmerman, 2001; Freixa et alii., 2002).

\section{Marco metodológico: investigación precedente, objetivos e instrumentos}

En estudios anteriores (Bayón, 2000; Calvi, 2006b; Carpi, 2010; Sanmartín, 2012), se ha señalado la compleja y confusa variedad denominativa existente para clasificar los establecimientos de alojamiento turístico en España, especialmente en la oferta rural: se registran más de 16 denominaciones genéricas (así, hotel, motel o parador) y 25 rurales (como cortijo o

1 Estas denominaciones formarían parte del léxico profesional de la hotelería y el turismo, de las palabras versadas sobre las estructuras y la organización turística, con un valor terminológico "establecido en la legislación pertinente, diferenciándose, por lo tanto, del significado corriente" (Calvi, 2006a: 58). Su complejidad conceptual no es equiparable a la terminología médica o similar. 
masía), sin tener en cuenta modalidades y especialidades de alojamiento ni compuestos con hotel (como hotel boutique u hotel spa). Esta variedad se enmarca en la potestad que poseen las comunidades autónomas españolas para legislar en torno a esta cuestión: acuñan denominaciones y formulan definiciones de los alojamientos sin guardar un acuerdo mínimo, lo que ocasiona un claro conflicto terminológico y conceptual ${ }^{2}$. El potencial usuario o cliente debe saber las distintas denominaciones y conceptos al cambiar de comunidad. En algunos casos se justifica esta heterogeneidad por la existencia de alojamientos pintorescos en cada lugar, los cuales responden a una arquitectura singular y requieren una denominación específica, como las casas cueva de Andalucía, los pazos en Galicia o las masías de la Comunidad Valenciana. Además, estas denominaciones sirven a unos fines estratégicos de promoción de estos productos, considerados como más típicos de una cultura, con una vinculación con la historia y con la arquitectura tradicional (Calvi, 2006b). Las propias instituciones turísticas impulsan la creación de un sello de identidad para diferenciarse las unas de las otras (Carpi, 2010).

Sin embargo, más allá de la arquitectura singular o del sello de identidad que impregnan estas denominaciones, no se entiende, por un lado, la heterogeneidad de términos que aparecen y desaparecen al cruzar comunidades (como pensión, que se convierte en residencia turística en Galicia) o se definen de un modo distinto en cada territorio. Se ha comprobado, además, que esta heterogeneidad denominativa de los textos legales no coincide con los usos reales en páginas web de promoción y que la norma internacional de estandarización, adaptada al español de España (UNE-EN ISO 1513, 2004), resulta parca y no se ajusta a la situación actual (Calvi, 2006b; Sanmartín, 2012).

Teniendo en cuenta la situación de España como referente, el objetivo de este artículo consiste en determinar la variedad de denominaciones (formales y conceptuales) de este campo nocional en Argentina, Chile y Costa Rica desde un triple enfoque contrastivo: desde la regulación legal, desde los usos reales y desde los diccionarios académicos. Así pues, los tres enfoques se materializan en tres objetivos específicos:

a) Describir, en su vertiente formal y conceptual, cómo se han regulado las diversas denominaciones de los establecimientos de alojamiento turístico en los textos legales del sector hotelero y en las normativas de estandarización de tres países: Argentina, Chile y Costa Rica.

b) Cotejar si esta regulación coincide con la variedad de denominaciones reales que los establecimientos utilizan en sus páginas web de promoción o con las denominaciones usadas por las instituciones oficiales de turismo en sus recursos informativos, ya sean buscadores de alojamiento o glosarios divulgativos.

c) Comprobar si las denominaciones reguladas se incorporan a los diccionarios académicos y si la definición lexicográfica integra aspectos de las definiciones técnicas de los textos legales.

Para alcanzar estos tres objetivos específicos, se establecen tres cauces distintos y sucesivos desde la perspectiva metodológica. El primer instrumento metodológico se ha fundamentado en la búsqueda de normativas o textos legales de los tres países seleccionados ${ }^{3}$ (Argentina,

2 La propia OMT en UNWTO (2010: 31) afirma: "Es preciso revisar la clasificación uniforme de los servicios de alojamiento turístico contenida en las Recomendaciones de 1993".

3 En 2012, las estadísticas de turistas internacionales de los países analizados son las siguientes: América cen- 
Chile y Costa Rica). Se trata de legislación sectorial, como leyes, reglamentos, ordenanzas y decretos, que regulan el turismo y el sector de la hotelería (Carpi, 2010). Se categorizan como géneros discursivos especializados del ámbito jurídico. Estos textos incorporan las denominaciones, como términos (en su vertiente formal), y las definiciones, como representación de la vertiente conceptual. También se han revisado algunas normas (lingüísticas) de estandarización del ámbito, en las que se registran las definiciones de las denominaciones (Tebé y Azarian, 2011). Para estos textos reservamos la etiqueta de normas o normas de estandarización con el fin de diferenciarlas de los textos legales anteriores (Gómez Sánchez, 2004). La relación completa de los textos citados figura en el Anexo I. Normas y legislación sectorial.

De estos documentos, se han extraído y analizado en cada país la diversidad de denominaciones reguladas de los establecimientos de alojamiento turístico (vertiente formal) y sus correspondientes definiciones (vertiente conceptual) para poder precisar su variedad denominativa y su complejidad conceptual. La extracción de denominaciones reguladas en cada país ha permitido elaborar un listado general de 44 voces en las tres zonas geográficas.

Como segundo instrumento metodológico, se ha comprobado si las denominaciones reguladas en cada país coinciden, desde la perspectiva formal y conceptual, con las denominaciones usadas en las páginas web comerciales de los establecimientos del país correspondiente y en los recursos elaborados por las instituciones. Las páginas web comerciales se dirigen al usuario general, lego en la materia, frente al destinatario especialista del texto legal. Describen las características del establecimiento, a modo de ficha técnica y/o folleto promocional tradicional.

Para cotejar las 44 denominaciones reguladas con las denominaciones reales, se ha recurrido a la inserción de las primeras en tres tipos de plataformas:

a) En el Corpus Multilingüe de Turismo de la Universitat de València (COMETVAL), de acceso restringido, que compila unas doscientas páginas web de tipos diversos de alojamientos de cada país.

b) En el buscador comercial de alojamientos Trivago (www.trivago.es).

c) En tres buscadores de alojamiento o de servicios turísticos, ubicados en las páginas institucionales de Argentina, Chile y Costa Rica (Véase el Anexo II. Páginas web institucionales). Este formato de recurso institucional ha posibilitado, como en el buscador comercial, una opción de búsqueda de las 44 denominaciones reguladas por palabras insertas en el nombre propio del establecimiento ("Busca por el nombre del servicio") y por "tipo de alojamientos". En el buscador institucional también se ha cotejado si las propias opciones de búsqueda presentadas como "tipos de alojamiento" (así, Departamentos y Suites) coinciden con las denominaciones reguladas. De este modo, se comprueba si las instituciones respetan la regulación del sector. Como herramienta auxiliar, para profundizar en este cotejo, se han revisado las definiciones breves incorporadas en uno de los buscadores o dos glosarios informativos elaborados por las propias instituciones, como es el caso de Argentina (Ministerio de

tral 8.872 millones (Costa Rica: 2.343), América del Sur 26.673 (Argentina: 5.599, Chile: 3.554) y América del Norte 106.683 (UNWTO, 2013). Estos tres países presentan mayor cantidad de turistas en sus respectivas zonas. El análisis general comprendía también la revisión de México, Perú, Honduras, Cuba, Colombia, Bolivia y Venezuela, cuyos resultados son similares a los países analizados, si bien el marco legal en cada país puede presentar diferencias. No se han podido presentar en este artículo por la extensión de los datos. 
Turismo. Presidencia de la Nación, 2013) y Chile (SERNATUR, 2008). Estos glosarios han permitido contrastar si la definición institucional coincide con la definición legal (vertiente conceptual).

Y, como tercera vía metodológica, se ha comprobado si estas denominaciones ya se han incorporado a las últimas ediciones de los diccionarios de carácter académico, al Diccionario de la lengua española, de la Real Academia española (2014), abreviado como [DRAE], y al Diccionario de Americanismos, de la Asociación de Academias de la Lengua Española (2010), abreviado como [DA].

\section{Análisis del corpus}

\subsection{Las denominaciones de alojamientos turísticos en Argentina}

En el caso de Argentina se han consultado una ley de ámbito nacional y tres decretos provinciales (Salta, Córdoba y Buenos Aires). Los resultados obtenidos han sido similares a lo que acontece en España: se evidencia una ambigüedad terminológica, a pesar de la insistencia de los textos legales en proteger los derechos del usuario.

Se constata que las tres denominaciones de la ley estatal se reproducen en los decretos provinciales (hotel, hostería y motel). Sin embargo, en los decretos se añaden seis denominaciones sin variantes sinonímicas (apart-hotel [aparthotel], hotel boutique, complejo especializado, complejo turístico, alojamiento turístico rural, casa de familia); seis denominaciones más con variantes, de carácter sinonímico, si bien consideramos la sinonimia como relativa y con grados diversos (Freixa et alii., 2002; Regueiro, 2010), e incluso una polisemia conceptual, en el caso de hostería, como se ilustra en la Tabla 1:

\begin{tabular}{|l|}
\hline cabaña / apart-cabaña / bungalow \\
\hline [conjunto de] casas / departamento \\
\hline hostería $^{\text {/ hostal }}$ \\
\hline hostería $^{2}$ / residencial / posada \\
\hline cama y desayuno / Bed \& Breakfast \\
\hline albergue de la juventud / hostel \\
\hline
\end{tabular}

Tabla 1. Variantes denominativas en la legislación turística argentina.

Así pues, en Argentina las denominaciones también oscilan, como en España, al cambiar de provincia. Las designaciones presentan una variación denominativa o diversidad sinonímica. La primera etiqueta resulta más adecuada en numerosos contextos, preferida también desde una perspectiva onomasiológica (Fernández Silva, 2013), dada la dificultad de establecer los sinónimos (Freixa, 2006): así, casa de familia parece que solo se diferencia del bed \& breakfast porque, según el decreto en el que aparece, en la primera los habitantes habituales no abandonan el inmueble.

Se han cotejado estas 24 denominaciones reguladas en Argentina con las reales en el corpus COMETVAL, en el buscador comercial Trivago y en el buscador de la página web 
institucional de la Provincia de Salta -con 481 registros de alojamientos-. También se ha ampliado el cotejo con las denominaciones reguladas en Chile y Costa Rica (un total de 44). El cotejo de datos se presenta en forma de Tabla sintética en el Apartado 3.5.

A continuación, se procede al comentario de las cuestiones más relevantes del contraste. Desde la perspectiva formal, en los considerados como usos reales de estas denominaciones, destaca la preferencia por el anglicismo frente al término patrimonial en el posible binomio sinonímico, como sucede en bed \& Breakfast / cama y desayuno o en hostel / albergue. Todos los alojamientos considerados como albergues en el buscador Trivago se denominan en sus respectivas páginas comerciales como hostel: "Hostel Buenos Aires -Recoleta El hostel está ubicado en el barrio de Recoleta, el corazón de Buenos Aires" (www.hirecoleta.com.ar). En el caso de Argentina, además, el término albergue adquiere un matiz distinto ('hotel que alquila habitaciones por horas para encuentros sexuales') cuando se le añade el adjetivo transitorio, tal y como se constata en la Guía de albergues transitorios (www.alberguestransitorios.com ).

A veces, la variación formal solo estriba en el empleo del guion; así sucede en apart hotel, cuya frecuencia de uso es abrumadora frente al compuesto con guion que se recoge en las normativas (apart-hotel): "Apart Hotel en el centro de la ciudad de Salta, departamentos totalmente equipados" (www.apartnubesdesalta.com.ar).

Por otro lado, el cotejo de datos en las tres plataformas ha permitido detectar dos denominaciones reguladas no utilizadas ([recinto de] campamento y casa de familia) y diez denominaciones usadas pero no reguladas en Argentina, como por ejemplo, resort, lodge o suites. En el primer caso, se aprecia una situación similar a la de España, en la que el anglicismo resort convive con expresiones sinonímicas como complejo turístico. Al igual que acontece en el caso de hostel y albergue, el anglicismo resort otorga modernidad y novedad. Se trata, pues, de una estrategia pragmática para hacer más atractivo el producto (Sanmartín, 2011; Estornell, 2013).

Más arduo resulta explicar el uso del anglicismo lodge, empleado en otras zonas para referirse a un establecimiento de alojamiento ubicado en entornos naturales para cazar, pescar y similares. Sin embargo, lodge, incorporado al nombre propio del hotel, alude a un alojamiento urbano en algunos de los textos registrados: "Tango Lodge es el primer Hotel de tango genuino en Buenos Aires" (www.tangohotelbuenosaires.com).

En tercer lugar, aparece con mucha frecuencia el sustantivo suites (préstamo del francés) en la denominación del nombre del hotel y a veces como equivalente de apartamento, muy distante del concepto de 'habitación de un hotel con dormitorio y salón separados', tal y como se define en DRAE: "Encuentre en Núñez Suites servicios ideales para terminar un día de trabajo. Un amplio ambiente con camas queen o twin y cocina totalmente equipada" (www.nunezsuites.com.ar).

Se constata una cuarta denominación, hotel boutique (o boutique hotel), que se ha extendido tanto que ha originado el desarrollo de una normativa específica para regularla: "El Boutique Hotel de la Fonte es un estilo de vida que se quiere compartir con otras personas que les gusta la naturaleza (...)" (www.bhfboutiquehotel.com). Boutique (préstamo del francés) se refiere en español a una tienda selecta, de ahí su uso en este compuesto léxico para referirse a un hotel exclusivo y singular.

En esta relación de ejemplos comentados, cabría incluir el término posada, solo documentado en una normativa como sinónimo de hostería ${ }^{2}$. Posada aparece de forma recurrente en el corpus de alojamientos, lo que indica un nuevo desajuste entre la realidad de 
las denominaciones y los textos legales: "Posada Angelus fue concebida con la misión de asumir el compromiso de brindar a cada uno de nuestros huéspedes un servicio singular" (www.posadaangelus.com.ar).

Por último, en el caso de las etiquetas de búsqueda por tipos de alojamiento del servidor institucional de Salta se aprecia bastante coincidencia con las denominaciones reguladas.

Desde la perspectiva conceptual, la situación también es similar a la de España. Las definiciones que aparecen en los textos legales presentan entre ellas una gran disparidad: en cuanto a los requisitos que debe poseer cada alojamiento (así, la oferta de plazas, el tener baño privado, no poderse considerar como hotel, o características de diseño y ubicarse en el medio natural). Véase, como muestra, hostería en dos textos legales, en los que, además, se indican distintas variantes denominativas o sinonímicas:

- hostería ${ }^{1}$ u hostal: Son aquellos establecimientos hoteleros que reúnen características de diseño arquitectónico acorde al medio natural y/o urbano en el que se encuentren situados. Tendrán una capacidad mínima de ocho (8) plazas en cuatro (4) habitaciones y una máxima de cincuenta y dos (52) plazas. (Decreto n. ${ }^{\circ} 659$ (Buenos Aires), 24-4-2007)

- hostería ${ }^{2}$ y/o posada: Establecimiento que brinda servicio de alojamiento en habitaciones individuales con baño privado, departamentos y suite, con una capacidad mínima de cinco (5) unidades de alojamiento, en el cual se preste el servicio de alojamiento y otros servicios complementarios, según los requisitos indicados para cada categoría, y que por sus características no puede ser encuadrado en la Clase Hotel. (Decreto n. ${ }^{\circ} 1359$ (Córdoba), 5-9-2000)

En el glosario Tesauro turístico argentino, editado por el Ministerio de Turismo. Presidencia de la Nación (2013: 19), la ambigüedad permanece y, además, surge un nuevo matiz que figura en otros países, 'casa donde se da comida': "Hostería: Casa donde se da comida y alojamiento mediante pago. Tradicionalmente se denomina hostería a los establecimientos de menos de 20 habitaciones con o sin servicios complementarios y un perfil de atención familiar".

En el cotejo de páginas web promoción de los alojamientos, se observa que el uso de una denominación específica no va seguido de una descripción rigurosa de las características que se indican en la normativa. Su carácter persuasivo justifica el empleo de las adjetivaciones positivas (como pintoresca, simple, cómoda o cálida, que aparecen en el ejemplo posterior) y no se atiende a las condiciones arquitectónicas que deben cumplir o al número de plazas que se ofertan: "Hostería Sir Thomas es una pintoresca hostería, (...) ofrece un cálido alojamiento, simple y cómodo con habitaciones dobles, triples y cuádruples, calefaccionadas, baño privado" (www.sirthomas.com.ar). Por ello, resulta difícil inferir el concepto que se desprende de estos usos contextuales, frente a las definiciones explícitas de las normativas. Tanto posada como hostería se consideran como denominaciones actuales que revitalizan palabras que remiten a antiguos establecimientos (Calvi, 2006b).

Ante esta diversidad denominativa y conceptual, surgen propuestas reguladoras, como las llevadas a cabo por la Secretaría de Turismo de la Nación (SECTUR) y el Instituto Argentino de Normalización y Certificación (IRAM). Estos elaboran diversas normas en 2008 y 2009. En estas normas se definen los tipos de alojamientos, si bien su objetivo principal es, en este caso, diseñar un sistema de calidad, tal y como se deduce del título, Norma Argentina IRAM SECTUR 42250 (24-06-2009) Alojamiento rural. Sistema de la calidad, la seguridad y el ambiente. En estas normas se definen solo algunos de los términos aparecidos en los párrafos anteriores: alojamiento rural, cabaña, hostel, hotel y casa de huéspedes (bed \& breakfast); y 
otros como campamento (camping). Por último, SECTUR publica en 2008 un folleto (Boto Álvarez, 2008), en el que se explican las nuevas modalidades de alojamiento, sin una repercusión legislativa, algunas de las cuales no se recogen en las normativas -indicadas con un asterisco*-: Bed \& Breakfast y B\&B; bungaloes, cabaña y *cottage; *coto y lodge; *ecolodge; hotel boutique; *hotel low cost; hostel; *spa; turismo rural, *agroturismo y *estancia. De hecho, en este mismo folleto se alude a la complejidad del problema terminológico:

Todas estas nuevas tendencias de alojamiento [...] se han convertido en un problema para el sector oficial que tiene a cargo la fiscalización hotelera, ya que en la mayoría de los casos no se encuadran dentro de las normativas/reglamentación de la legislación vigente. [...] Cada provincia cuenta con su propia legislación hotelera, enmarcada dentro del espíritu federal que caracteriza a la actividad (Boto Álvarez, 2008: 40).

\subsection{Las denominaciones de alojamientos turísticos en Chile}

En el caso de Chile, el Servicio Nacional de Turismo de Chile, SERNATUR, se ha convertido en un organismo reconocido capaz de ejecutar una política de ámbito nacional para promover y difundir el desarrollo de la actividad turística de Chile. Este país cuenta, además, con una ley nacional de turismo desde 2010, en la que se señala la obligatoriedad de los prestadores de los servicios de turismo (alojamiento) de respetar las leyes de ámbito nacional e inscribirse en el Registro de un modo correcto. En el folleto informativo titulado Ley 20.423 y el Nuevo Sistema de Registro se afirma que los servicios de alojamiento turístico deberán promocionarse y difundirse de acuerdo con el registro oficial. Además, el Instituto Nacional de Normalización, INN, elabora las normas de estandarización terminológica de los establecimientos de alojamiento turístico, con el objetivo de ayudar al usuario para decidir al facilitar la información sobre el servicio y aumentar de este modo su satisfacción.

Así pues, Chile se presenta como un país con un modelo de estandarización preciso en el terreno de las denominaciones de los distintos alojamientos turísticos. Sin embargo, esto no impide que exista sinonimia en torno a las denominaciones (Sanmartín, 2011). Se han consultado dieciséis normas de ámbito nacional en relación con la clasificación de los alojamientos, Normas Chilenas Oficiales. En estas normas se insiste de nuevo en la importancia de indicar correctamente y sin ambigüedades el tipo de establecimiento: "Consignar en forma precisa y explícita el nombre de fantasía y su clase, en los medios publicitarios, correspondencia, formularios y cualquier otra documentación o material de propaganda que se utilice" (NCh2963.Of2006: 12).

Se han cotejado las 24 denominaciones de las normas, en especial de la más genérica, Clasificación, calificación y terminología de los establecimientos de alojamiento turístico NCh2760.Of2007, con las indicadas como opciones de búsqueda ("Tipos de alojamientos") por el propio servidor de SERNATUR para comprobar el uso de estas variantes sinonímicas y si el buscador respeta la terminología propuesta. En dicho buscador se añade una breve definición de casi todos los tipos de alojamiento. También se han cotejado con los 2.222 registros

4 En 2010 la Subsecretaría de Desarrollo Turístico publica un informe, Oferta de Alojamientos en Argentina 2009, en el que se citan nuevos términos como pensiones, hoteles sindicales y municipales, tiempo compartido y hospedaje, entre otros. Sirva esto como prueba de que la diversidad de denominaciones resulta sumamente compleja: a más documentos, nuevos términos. 
de establecimientos que integra el buscador. En el caso de Chile este buscador se ha considerado como la referencia de contraste fundamental por el número de registros que integra.

En el cotejo realizado se observa que las etiquetas de búsqueda del servidor siguen la propuesta de las normas, si bien reducen la sinonimia al suprimir algunos equivalentes patrimoniales, tal y como se indica con un asterisco en la Tabla 2. Estos equivalentes tampoco se han documentado en los propios registros de alojamientos del servidor.

\begin{tabular}{|l|}
\hline Bed \& Breakfast / alojamiento familiar \\
\hline camping / *recinto de campamento \\
\hline lodge / *centro de turismo de naturaleza \\
\hline resort / complejo turístico \\
\hline hostel / albergue / refugio \\
\hline hacienda / estancia / hospedaje rural \\
\hline cabañas / *bungalow / *bungaló \\
\hline
\end{tabular}

Tabla 2. Variantes denominativas en las normas de estandarización chilenas.

En algunos casos, como hospedaje rural, realmente se trata de una especie de hiperónimo respecto a estancia y hacienda más que de un sinónimo; de ahí la dificultad de establecer las relaciones conceptuales.

En esta variación sinonímica suele competir el término patrimonial (alojamiento familiar) con el anglicismo (Bed \& Breakfast). Este último impregna de una connotación de modernidad y esnobismo el objeto de referencia. A pesar de la transparencia semántica que ofrece la denominación patrimonial, generalmente formada por un mecanismo de composición sintagmática (sustantivo + adjetivo), no consigue desplazar al anglicismo. Otra cuestión distinta es averiguar qué denominación fue la primera, esto es, saber si el término patrimonial deviene una propuesta para buscar una equivalencia a un anglicismo ya consolidado, o, al revés, ya existía el término patrimonial y surge el anglicismo para conceder ese toque de modernidad (Sanmartín, 2011; Giménez, 2013). Probablemente, el primer caso se dé con Bed \& Breakfast y alojamiento familiar, y el segundo con hostel frente a albergue o refugio.

Si se toma como punto de referencia, Bed \& Breakfast y alojamiento familiar, se comprueba que en los registros del buscador institucional Bed \& Breakfast aparece de forma abrumadora (50 veces) y alojamiento familiar esporádicamente (3 veces) en el nombre propio del establecimiento. Además, la denominación alojamiento familiar alterna con hospedaje familiar (7 veces): "Bed And Breakfast Casa Bonita, B\&b La Codorniz, Alojamiento Familiar Onde Nacho, Hospedaje Familiar Casa de Toya" (www.sernatur.cl/buscador-de-servicios).

Los términos sin sinónimos de la Norma son los siguientes: departamentos, hostal, residencial, hostería, hotel, termas, apart-hotel, hotel boutique y motel. Si se coteja con las opciones de búsqueda del servidor, se aprecia que el servidor sigue las denominaciones de la norma, y solo desaparece como opción motel y se añade suites. Curiosamente, el 
servidor permite la búsqueda de cabañas y en la definición sucinta que se ofrece se considera como equivalente a motel: "Motel o Cabañas: servicio de alojamiento turístico en unidades habitacionales privadas, accesible desde el nivel de suelo mediante circulaciones públicas exteriores" (www.sernatur.cl/buscador-de-servicios).

$\mathrm{Al}$ revisar los registros integrados en el buscador, se observa que en los nombres propios de los establecimientos aparecen usos marcadamente estratégicos: así se emplean los formantes eco y boutique en el nombre propio de los establecimientos, como sucede en "Eco hostel" o "Casaltura Hostel Boutique". También se constatan denominaciones de establecimientos no contempladas en las normas, como centro recreacional, centro vacacional o posada, pero reguladas en otros países.

La norma más genérica mencionada, reeditada en $2013^{5}$, ha simplificado y modificado cuestiones terminológicas de la edición anterior, publicada en 2007. Así por ejemplo, se ha suprimido el término bungaló o bungalow como equivalente de cabaña, aparece hotel boutique como un nuevo término y concepto y, además, se especifican en la nueva norma aspectos obligatorios relativos al servicio (como servicio de mucama o servicio de recepción) y no solo cuestiones estructurales de edificación. En casi todas las definiciones de los términos se han añadido estas precisiones sobre los servicios.

En síntesis, las normas cambian y se modifican para intentar ajustarse a las nuevas tipologías (como ocurre con hotel boutique), simplificar la variación terminológica (al suprimir bungaló) o precisar y actualizar los conceptos.

En esta parte definitoria de los conceptos, tanto en la norma como en un glosario elaborado por la Institución (SERNATUR, 2008), no se indica un mínimo de plazas ofertadas ni elementos arquitectónicos o dimensiones, a diferencia de lo documentado en Argentina. Se insiste sobre todo en los servicios que se ofrecen, si bien difieren en aspectos, como contar con estacionamientos de vehículos o ubicarse en zona rural:

Hostería. Establecimiento en que se provee servicio de alimentación en un restaurante, además de alojamiento turístico en habitaciones u otro tipo de unidades habitacionales privadas, ubicado en lugares suburbanos o rurales. Disponen además de facilidades para el estacionamiento de vehículos, ubicados preferentemente junto al edificio principal, sin perjuicio de proporcionar otros servicios complementarios. (SERNATUR, 2008: 55)

\subsection{Las denominaciones de alojamientos turísticos en Costa Rica}

En el Proyecto de Ley General del Turismo, 2008, se articula la existencia de un Registro Nacional de Turismo en el artículo 46. Con anterioridad, existía el Reglamento de las empresas de hospedaje turístico, publicado en 1980, que cuenta con sucesivas reformas (desde 1980 a 2013). En el Reglamento y en decretos/reformas posteriores se definen con precisión los 12 tipos de establecimientos de alojamiento, algunos de los cuales no figu-

5 En total, se describen 17 tipos de establecimientos con sus correspondientes denominaciones. Se podría considerar como un modelo riguroso. En cambio, en la norma internacional, ISO 18513 -2003 se reducen las denominaciones, ya que solo se conservan las más genéricas: hotel, suite hotel, aparhotel, apartamento turístico (complejo de apartamentos), bungalow o chalé, motel, camping, albergue juvenil; se introducen dos denominaciones más singulares (residencia y casa de huéspedes); y se añaden dos nuevas que no figuran entre las denominaciones americanas (hotel balneario y centro vacacional). 
ran en otros países, como botel, condohotel o cabina: 1. Hoteles 2. Hoteles-Residencia 3. Apartotel 4. Condohoteles 5. Moteles Turísticos 6. Hoteles en tiempo compartido 7. Boteles 8. Pensiones 9. Casa de Huéspedes 10. Albergues 11. Grupo Campamentos 12. Viviendas Turísticas (Cabina, Apartamentos, Cabañas). Los requisitos que figuran en las definiciones no son similares a los de otros países. Así por ejemplo, en villas / cabañas / cabinas se alude al número de unidades habitaciones o a su ubicación:

Villas / Cabañas / Cabinas: Establecimiento que brinda servicio de hospedaje por una tarifa diaria, conformando un grupo homogéneo de al menos siete unidades habitacionales, cada una con baño privado, uno o más dormitorios, sala comedor y cocina, ubicadas generalmente en la playa, ríos, lagos y montañas. (Reglamento de las empresas de hospedaje turístico, 1980-2013) (Costa Rica)

Cabaña. Unidad Habitacional aislada de un establecimiento turístico, destinada a brindar facilidades de alojamiento turístico y permanencia a una o más personas según su capacidad, y que cuenta como mínimo con las áreas siguientes: dormitorio, sala de estar, cocina, comedor y baño, y los demás servicios que para cada categoría se indiquen. (SERNATUR, 2008: 57) (Chile)

También sorprende la definición que se ofrece de casa de huéspedes como un "establecimiento semejante a la pensión que no ofrece servicio de alimentación", dado que no coincide con la definición que se ofrece, por ejemplo en $D R A E$, en la que no se considera este requisito.

El Sitio Oficial Costa Rica, Sin ingredientes Artificiales http://www.visitcostarica.com ofrece un directorio de 500 alojamientos, organizado solo por etiquetas muy genéricas como Hoteles Boutique, Hoteles con CST, Hoteles por Región, Hoteles por Categoría y Hoteles por Servicio. En este sentido, el buscador no integra ni permite la búsqueda de las denominaciones reguladas. Ahora bien, ha sido posible cotejarlas en este directorio en la opción de búsqueda por nombre del establecimiento, siempre y cuando la denominación se encuentre integrada en el nombre propio. También se ha empleado en el cotejo el corpus COMETVAL y el buscador Trivago.

Los resultados obtenidos han sido similares a los países anteriores. Existen desajustes entre las denominaciones reguladas y las reales: no se ha podido registrar en los usos reales denominaciones como hotel residencia, botel o recinto de campamento.

Además, en los usos reales se detectan nuevas denominaciones. Sirvan como muestra las siguientes denominaciones: lodge (Selva bananito Lodge http://www.selvabananito.com), suite (Hotel y suites Bahía del Sol http://www.bahiadelsolhotel.com/index.aspx) o resort (Hilton Papagayo Resort www.hiltonpapagayoresort.com). De nuevo, se trata de un desajuste más entre normativas y usos reales.

\subsection{Las denominaciones en diccionarios académicos}

Algunas de las denominaciones de los establecimientos de alojamiento también acaban registradas en los diccionarios generales. Para comprobar qué denominaciones se han sancionado y cómo se han definido, se han revisado dos diccionarios. Estos diccionarios se han seleccionado porque han sido elaborados por academias de la lengua y se consideran dos referencias fundamentales en español. Además, presentan ediciones recientes: el Diccionario de la lengua Española, de la Real Academia Española (2014) [DRAE], en su 
última edición, 23a ; y el Diccionario de Americanismos, de la Asociación de Academias de la Lengua Española (2010) [DA], escogido también por incorporar de un modo global todas las variedades del español de América con metodología contrastiva con el español general.

En $D R A E$ numerosos lemas solo presentan acepciones vinculadas a tipos de construcciones, pero no se alude a su consideración como alojamientos turísticos: hacienda (como finca agrícola), estancia (considerada como americanismo, hacienda de campo destinada al cultivo, y más especialmente, a la ganadería), apartamento o departamento (como piso), villa, (como casa de recreo situada aisladamente en el campo), bungaló o el americanismo cabaña (como casa pequeña de una sola planta que se suele construir en parajes destinados al descanso). Refugio se considera como un edificio en la montaña, si bien destinado a viajeros.

En otras voces destaca la vaguedad con que se definen a partir del hiperónimo casa, ya que pensión y casa de huéspedes solo se diferencian de hostal y hostería en que las primeras ofrecen alojamiento, y los segundos también comida. Por su parte, hotel, albergue y posada (en la 23. a) se definen respectivamente con el hiperónimo 'establecimiento de hostelería, hotelero, hotelero moderno y público', y se diferencian únicamente por unos rasgos sémicos poco específicos: la comodidad del hotel, las estancias cortas del albergue o evocar a las antiguas posadas en posada. Tan solo motel aparece definido con mayor precisión. Por su parte, suite se concibe como un tipo de habitación de hotel. Es notoria la ausencia de los tipos de hotel a modo de compuestos sintagmáticos denominativos (Sanmartín, 2012), quizá porque se consideran que poseen un sentido transparente. He aquí una muestra de las definiciones comentadas:

hotel. m. Establecimiento de hostelería capaz de alojar con comodidad a huéspedes o viajeros.

hostería f. Casa donde se da comida y alojamiento mediante pago.

motel. m. Establecimiento público, situado generalmente fuera de los núcleos urbanos y en las proximidades de las carreteras, en el que se facilita alojamiento en departamentos con entradas independientes desde el exterior, y con garajes o cobertizos para automóviles, próximos o contiguos a aquellos.

Por su parte, en el $D A$ casi todos los compuestos con el término hotel presentan una vinculación con el alquiler de habitaciones para encuentros sexuales, al igual que sucede con motel, posada y residencia:

motel. I. 1.m. Mx, ES, Ni, CR, RD, PR, Co, Ve, Ec, Bo, Py, Ur. Establecimiento en el que se alquilan habitaciones a parejas para tener relaciones sexuales, y a las que se llega por medio de un vehículo.

El $D A$ recoge el matiz de 'apartamento' que conlleva la variante formal suit; la consideración de cabina como tipo de casa; o del residencial, la cabaña y el lodge como alojamientos turísticos:

suit. f. Ec. Departamento pequeño, generalmente con un solo dormitorio o de un solo ambiente.

cabina $\mathrm{f} C R$. Casa pequeña que se construye cerca de la playa para vacacionar. 
cabaña f. $G u, H o, E S, N i, C u, P R, C h$. Casa pequeña, generalmente de una planta, que se construye dentro de hoteles o centros de recreación para ser alquilada.

residencial f. $E c, B o, C h, A r, U r ; m$. Ar. Casa de huéspedes, pensión.

lodge $\mathrm{m}$. Es. Ch. S. Pe. Establecimiento turístico hotelero situado en una zona rural.

Así pues, muchas de estas voces presentan acepciones dispares desde una perspectiva contrastiva peninsular o diferencial, como sucede con cabaña, suit o casa de huéspedes; o incluso no se utilizan en todas las zonas del español, como tipo de alojamiento turístico (como sucede con lodge).

En síntesis, estos diccionarios generales no dan cuenta de la realidad lingüística compleja de este ámbito temático, ya que no atestiguan la variedad de voces (terma o botel), en especial no incluyen las más novedosas o neológicas (resort, bed \& brekfast, hotel boutique, condohotel, etc.). Como apunta Contreras (2008), terminología, variación lingüística y lexicografía deberían establecer una relación más estrecha.

En el diccionario tampoco se da cuenta de la complejidad conceptual: no se precisan los requisitos técnicos esenciales para poder recibir tales denominaciones, tal y como se detallan en las definiciones de los textos legales. Este hecho se explica porque las definiciones pertenecen a diccionarios generales no especializados (Calvi, 2006a; Sanmartín, 2012). Un ejemplo paradigmático de la conceptualización dispar de este ámbito lo constituye motel. En los textos legales se define de un modo preciso, si se compara con la definición de los diccionarios anteriores:

Motel: Aquellos establecimientos que se encuentren ubicados sobre rutas o caminos, en los cuales se preste al turista el servicio de alojamiento y los demás que para cada categoría se indiquen, en unidades habitacionales con ingresos independientes o aislados entre sí, contando con estacionamiento contiguos o próximos a habitaciones, en cantidades iguales a éstas. La capacidad mínima de dichos establecimientos será de veinte (20) plazas en diez habitaciones. Moteles de 3, 2 y 1 estrellas. (Decreto n. ${ }^{\circ} 1125$ (Salta), 14-8-1980)

Esta definición coincide con la definición del $D R A E$, pero se aleja de la conceptualización encontrada en el $D A$ y en los textos reales de promoción tanto en España como en América. En los textos reales se insiste en la confianza, privacidad e intimidad que concede este tipo de alojamiento y en la singularidad de la decoración de sus habitaciones: "En Motel El castillo ofrecemos: Albergue transitorio. Recepción las 24 horas. 24 habitaciones especiales. 4 habitaciones en suite con hidromasajes. 24 habitaciones temáticas. Ambiente climatizado" (www.motelelcastillo.com.ar).

\subsection{Síntesis de resultados}

Véase, como síntesis general de la investigación, la Tabla 3, en la que se reproducen todas las denominaciones halladas en los textos legales y en el uso real (del corpus revisado) de los tres países, y en los diccionarios. Se indica un asterisco en los diccionarios cuando la acepción no se encuentra vinculada a un tipo de establecimiento turístico y solo remite a un tipo de edificación. En negrita se destacan las denominaciones más coincidentes. En colores grises se han agrupado las posibles variantes denominativas, y en color azul las más discutibles: 


\begin{tabular}{|c|c|c|c|c|c|c|c|}
\hline \multirow{3}{*}{ apartotel / apart hotel } & \multicolumn{2}{|c|}{ Argentina } & \multicolumn{2}{|c|}{ Chile } & \multicolumn{2}{|c|}{ Costa Rica } & \multirow{3}{*}{$\begin{array}{c}\text { Diccionarios } \\
D R A E / D A \\
D R A E \text { (apartotel) }\end{array}$} \\
\hline & \multicolumn{2}{|c|}{ ley-norma / uso } & \multicolumn{2}{|c|}{ norma / uso } & \multicolumn{2}{|c|}{ ley/uso } & \\
\hline & $\mathrm{X}$ & $\&$ & $\mathrm{X}$ & $\&$ & $\mathrm{X}$ & $\&$ & \\
\hline motel & $\mathrm{X}$ & $\&$ & $\mathrm{X}$ & $\&$ & $\mathrm{X}$ & $\&$ & $D R A E$ \\
\hline motel $^{2 \text { (por horas) }}$ & & $\&$ & & $\&$ & & $\&$ & $D A$ \\
\hline hotel & $\mathrm{X}$ & $\&$ & $\mathrm{X}$ & $\&$ & $\mathrm{X}$ & $\&$ & $D R A E$ \\
\hline h. residencia & & & & & $\mathrm{X}$ & & \\
\hline h. boutique & $\mathrm{X}$ & $\&$ & $\mathrm{X}$ & $\&$ & & $\&$ & \\
\hline h. en tiempo compartido & & $\&$ & & & $\mathrm{X}$ & $\&$ & \\
\hline termas & & $\&$ & $\mathrm{X}$ & $\&$ & & & DRAE* \\
\hline condohotel / condo-hotel & & $\&$ & & $\&$ & $\mathrm{X}$ & $\&$ & \\
\hline -resort & & $\&$ & $\mathrm{X}$ & $\&$ & & $\&$ & \\
\hline -complejo turístico & $\mathrm{X}$ & $\&$ & $\mathrm{X}$ & $\&$ & & $\&$ & \\
\hline complejo especializado & $\mathrm{X}$ & $\&$ & & & & & \\
\hline -hostería ${ }^{1 \text { (diseño arquitectónico/natural) }}$ & $\mathrm{X}$ & $\&$ & & $\&$ & & & \\
\hline -hostal ${ }^{1 \text { (diseño arquitectónico/natural) }}$ & $\mathrm{X}$ & $\&$ & & & & $\&$ & \\
\hline -hostería 3 (restaurante) & & & $\mathrm{X}$ & $\&$ & & & \\
\hline -hostería ${ }^{2}$ (inferior a un hotel) & $\mathrm{X}$ & & & $\&$ & & & DRAE \\
\hline -hostal 2 (inferior a un hotel) & & & $\mathrm{X}$ & $\&$ & & & $D R A E$ \\
\hline -posada & $\mathrm{X}$ & $\&$ & & $\&$ & & $\&$ & DRAE \\
\hline -pensión & & & & & $\mathrm{X}$ & $\&$ & $D R A E$ \\
\hline -residencial & $\mathrm{X}$ & $\&$ & $\mathrm{X}$ & $\&$ & & & $D A$ \\
\hline -casa de huéspedes ${ }^{\text {(sin alimentación) }}$ & & & & & $\mathrm{X}$ & $\&$ & $D R A E$ \\
\hline -alojamiento turístico rural & $\mathrm{X}$ & & & & & & \\
\hline -hospedaje rural (genérico) & & $\&$ & $\mathrm{X}$ & $\&$ & & & \\
\hline -hacienda & & $\&$ & $\mathrm{X}$ & $\&$ & & $\&$ & $D R A E^{*} / D A^{*}$ \\
\hline -estancia & & $\&$ & $\mathrm{X}$ & $\&$ & & & $D R A E^{*} / D A^{*}$ \\
\hline -ecolodge & & $\&$ & & $\&$ & & $\&$ & \\
\hline -lodge & & $\&$ & $\mathrm{X}$ & $\&$ & & $\&$ & $D A$ \\
\hline -centro de turismo de naturaleza & & & $\mathrm{X}$ & & & & \\
\hline -departamento & $\mathrm{X}$ & $\&$ & $\mathrm{X}$ & $\&$ & & & $D R A E^{*}$ \\
\hline -apartamento & & & & & $\mathrm{X}$ & $\&$ & $D R A E^{*}$ \\
\hline -[conjunto de] casas & $\mathrm{X}$ & $\&$ & & & & & \\
\hline - suite / suit & & $\&$ & & & & $\&$ & $D A$ \\
\hline -bed \& breakfast & $\mathrm{X}$ & $\&$ & $\mathrm{X}$ & $\&$ & & $\&$ & \\
\hline -alojamiento familiar & & $\&$ & $\mathrm{X}$ & & & & \\
\hline -cama y desayuno & $\mathrm{X}$ & & & & & & \\
\hline casa de familia & $\mathrm{X}$ & & & & & & \\
\hline -villa & & & & & $\mathrm{X}$ & $\&$ & DRAE* \\
\hline -bungalow / bungaló & $\mathrm{X}$ & $\&$ & $\mathrm{X}$ & $\&$ & & $\&$ & $D R A E^{*}$ \\
\hline -cabaña & $\mathrm{X}$ & $\&$ & & $\&$ & $\mathrm{X}$ & $\&$ & $D R A E^{*} / D A$ \\
\hline -apartcabañas & $X$ & $\&$ & & & & & \\
\hline -cabina & & & & & $\mathrm{X}$ & $\&$ & $D A^{*}$ \\
\hline -camping & $\mathrm{X}$ & $\&$ & $\mathrm{X}$ & $\&$ & & $\&$ & $D R A E$ \\
\hline -[recinto de] campamento & $\mathrm{X}$ & & $\mathrm{X}$ & & $\mathrm{X}$ & & $D R A E$ \\
\hline botel & & & & & $\mathrm{X}$ & & \\
\hline -albergue [juvenil/ de la Juventud] & $\mathrm{X}$ & $\&$ & $\mathrm{X}$ & $\&$ & $\mathrm{X}$ & $\&$ & DRAE \\
\hline -hostel & $\mathrm{X}$ & $\&$ & $\mathrm{X}$ & $\&$ & & $\&$ & \\
\hline -refugio $^{\text {(montaña) }}$ & & $\&$ & $\mathrm{X}$ & $\&$ & & & $D R A E$ \\
\hline
\end{tabular}

Tabla 3. Denominaciones en los diferentes países y en los diccionarios. 


\section{Conclusiones}

Los países que han sido objeto de este análisis -Argentina, Chile y Costa Rica- muestran unas normativas muy dispares, tanto en lo relativo a su sistema de clasificación como a su posible consulta pública o accesibilidad por parte de cualquier usuario. En este sentido, Chile se configura como una excepción y un paradigma por la precisión y actualización de sus normas de estandarización y por la facilidad de su consulta para el usuario en general. Costa Rica también aspira a un modelo de clasificación estatal, pero no posee la exhaustividad del desarrollo de normas de estandarización de Chile. En el caso de Argentina, como en el de España, el usuario accede a distintos tipos de leyes y decretos de ámbitos estatales y provinciales (véanse como muestra, Córdoba, Salta o Buenos Aires) sin la claridad del ejemplo chileno.

Las instituciones o ministerios, además de legislar para poder ofrecer un sistema de clasificación riguroso, suelen crear un registro unificado de prestadores del servicio, conectado en ocasiones con un buscador para el usuario/turista del producto. En estos buscadores institucionales de alojamientos no siempre se sigue la propuesta terminológica desarrollada en las normativas.

Destaca también la divergencia entre las denominaciones reguladas y los usos estratégicos que llevan a cabo los propietarios de los establecimientos: en el nombre propio del establecimiento (o nombre fantasía) se utilizan las denominaciones consideradas como más persuasivas para que el cliente se aloje en el establecimiento (desde ecolodge a hotel boutique o resort). Este fenómeno también se repite en el texto descriptivo que aparece en la web del establecimiento, en el que se juega con denominaciones que no se corresponden con lo señalado en la legislación correspondiente.

De hecho, si se comparan las denominaciones existentes en las diversas legislaciones y normas de estandarización de los tres países (sintetizados en la Tabla 3, del apartado anterior), se observa, por un lado, una gran variedad de denominaciones, ya resulten estrictamente sinonímicas o no, cuya definición no siempre aparece expresada con precisión; por otro lado, se constata, como se ha indicado en el párrafo anterior, un desajuste entre las denominaciones de la legislación y de las normas, y las designaciones documentadas en páginas web comerciales o en buscadores institucionales.

Existen unas denominaciones -sin sinónimos léxicos- más o menos genéricas, consolidadas y constantes en todos los países (hotel, motel y apartotel) o recientes y novedosas (hotel boutique), y otras que se utilizan solo en algunos países (como terma, cabina o condohotel), lo que podría considerarse como diversidad léxica condicionada por lo geolectal. La acuñación de nuevas denominaciones para nuevas modalidades de alojamiento responde a veces a una estrategia de promoción para vender productos originales y singulares (Estornell, 2013). Es un modo de reinventarse (hotel boutique), si bien también surgen realmente nuevas modalidades hoteleras, como el condohotel.

Las denominaciones biunívocas constituyen una excepción, frente a la polisemia conceptual (o variación conceptual) y a la sinonimia denominativa (o variación denominativa). En el ámbito de los alojamientos se proponen numerosas designaciones que conviven a modo de variantes sinonímicas de diversos tipos: las meras variantes gráficas (bungalow / bungaló; apart hotel / apartotel/ apart-hotel), las variantes léxicas opcionales ([conjunto] de casas), las variantes morfológicas (albergue de la juventud / juvenil), las variantes por siglas (Bed \& Breakfast / $B \& B$ ) y las variantes léxicas.

Entre las variantes léxicas destacan dos tipos: aquellas formadas por voces más o menos patrimoniales o por una voz patrimonial y un préstamo. El mayor o menor grado de lo pa- 
trimonial depende del proceso de integración del préstamo en español. Así, en los ejemplos que a continuación se indican aparecen préstamos ya incorporados a nuestra lengua (apartamento / departamento (préstamo del francés); villa / bungaló (préstamo del inglés de origen hindi) / cabaña). De hecho, la propia voz hotel era en su origen un galicismo.

Téngase en cuenta que la sinonimia léxica responde fundamentalmente a una concurrencia entre el término patrimonial y el anglicismo y, en menor medida, el galicismo, como ya se ha explicado a lo largo de estas páginas: resort / complejo turístico; lodge / centro de naturaleza; hostel / albergue; bed \& breakfast /cama y desayuno, camping / campamento, etc. En algunos casos, el anglicismo surge primero y después el término patrimonial a modo de normalización (cama y desayuno); en otros casos al revés (albergue). En las páginas web comerciales y en los nombres propios de los establecimientos existe una marcada preferencia por el préstamo, ya que connota cierta modernidad y novedad.

De lo expuesto hasta aquí, se infiere el reconocimiento de una variación denominativa en la que convergen dos aspectos: el tipo discursivo o tenor interaccional y el proceso de creación léxica. Así, mientras los textos legales y normas apuestan por las voces patrimoniales, en los textos de promoción se opta por el préstamo, generalmente, por el anglicismo como una apropiación de la connotación de modernidad.

Por otra parte, en la denominación de ciertos establecimientos, se revitalizan voces de antiguos alojamientos para acentuar el sabor local y lo pintoresco: hacienda / estancia; hostal / hostería / posada. Sin embargo, en estas voces surge el problema de la ambigüedad conceptual, ya que no existe unanimidad en los distintos países para definir estos términos. Cada país o provincia impone su conceptualización, como si de una corriente investigadora o escuela de pensamiento se tratara (Fernández Silva, 2013).

Así pues, las distintas denominaciones permiten reconocer diferentes estrategias pragmalingüísticas que comprenden desde la modernidad otorgada por el anglicismo (resort) al sabor local del término patrimonial (hacienda, posada) (Calvi 2006b). Además, el acuñar nuevos términos como hotel boutique o condohotel supone incrementar la complejidad denominativa de un ámbito, que, como corresponde a cualquier producto comercial, intenta ofertar tipos de alojamientos relativamente novedosos.

La variación denominativa se combina con la variación conceptual, puesto que algunas de estas voces (como hostería) son definidas de distinto modo en las leyes y normas de los países analizados (Tebé y Azarian, 2011), bien porque se tienen en cuenta diferentes rasgos o parámetros en las definiciones (de los elementos arquitectónicos o instalaciones a los servicios ofertados), bien porque reflejan diversas conceptualizaciones de la realidad.

Como era esperable, cuando estas voces se definen en los diccionarios generales se opta por definiciones amplias que no reflejan la complejidad de la descripción terminológica de las leyes y normas (el conocimiento más especializado), sino que se corresponden más con los conocimientos de un profano en la materia. Justamente en los textos legales se insiste en que las denominaciones que aparecen en los textos de promoción y comerciales se correspondan con lo indicado en la ley para no crear ambigüedades.

En suma, la pretendida globalización del léxico hispánico (López Morales, 2006) contrasta con la variedad léxica geolectal, con la variedad léxica discursiva y con sus estrategias pragmalingüísticas vinculadas: de los hostels a los albergues e incluso a los albergues transitorios. De momento, las normas internacionales del sector no reflejan ni la variedad léxica geolectal ni la discursiva, con sus variantes denominativas y conceptuales. 


\section{Referencias bibliográficas}

Arcarons, R., Goitia, V. y González, N. (2008): "La clasificación hotelera en la Unión Europea: un mercado poco común", Papers de turismo, 43-44, págs. 49-67: http://www.estig.ipbeja.pt/ ac_ direito/ ClassHotUEMercadoPoco Comun.rtf (05-11-2012)

Asociación de Academias de la Lengua Española (2010): Diccionario de americanismos. http://www. asale.org (05-11-2012)

Bayón, F. (2000): Unidad del Mercado Turístico Español: http://www.mesadelturismo.com/common/ $\mathrm{mt} / \mathrm{unidad} /$ tematico.php3 (05-11-2012)

Boto Álvarez, L. (2008): Nuevas modalidades de alojamiento. Secretaría de Turismo de la Nación: http://2016.turismo.gov.ar/wp_turismo/wp-content/uploads/2009/06/nuevas-modalidades-dealojamiento.pdf (05-11-2012)

Cabré, M.T. (1999): La terminología. Representación y comunicación. Una teoría de base comunicativa $y$ otros artículos. Barcelona, IULA/UPF.

Calvi, M.V. (2006a): Lengua y comunicación en el español del turismo. Madrid, Arco Libro.

Calvi, M.V. (2006b): "El uso de términos culturales en el lenguaje del turismo: los hoteles y su descripción". En Calvi, M.V. y L. Chierichetti (eds.): Nuevas tendencias en el discurso de especialidad. Bern, Peter Lang, págs. 271-292.

Carpi, E. (2010): "Las denominaciones de los establecimientos de alojamiento turístico en la normativa española". En Chierichetti, L. y G. Garofalo (eds.): Lengua y derecho: líneas de investigación interdisciplinaria. Bern, Peter Lang, págs. 65-91.

Ciapuscio, G.E. (2006): Textos especializados y terminología. Barcelona, IULA/ UPF.

Condamines, A. (2010): "Variations in Terminology Application to the Management of Risks Related to Language Use in the Workplace", Terminology, 16 (1), págs. 30-50.

Estornell, M. (2013): “Aproximación al léxico del turismo activo: codificación lexicográfica, formación y variación denominativa”, Normas. Revista de Estudios Hispánicos, 3, págs. 33-55.

Contreras, N.M. (2008): El diccionario de lengua y el conocimiento especializado en la sociedad actual. Jaén, Universidad de Jaén.

Fernández Silva, S. (2013): "La influencia del área disciplinar en la variación terminológica: Un estudio en un corpus interdisciplinario sobre pesca”, Revista Signos. Estudios de Lingüística, 46 (83), págs. 361-388.

Freixa, J. (2006): "Causes of Denominative Variation in Terminology: A Typology Proposal", Terminology 12(1), págs. 51-77.

Freixa, J., Kostina, I y Cabré, M.T. (2002): "La variación terminológica en las aplicaciones terminográficas". Ponencia presentada en VIII Simposio Iberoamericano de terminología, Cartagena de Indias.

Giménez, D. (2013): "El léxico del turismo en el español de Argentina: estudio de las principales páginas web hoteleras", Normas. Revista de Estudios Lingüísticos Hispánicos, 3, págs. 57-76.

Gómez Sánchez, A.F. (2004): "Las normas como recurso para la traducción especializada: tipología desde el punto de vista terminológico y su utilidad para el traductor". En González, L. y P. Hernúñez (coords.): Las palabras del traductor, Bruselas, Eslerta, págs. 399-409.

Lebsanft, F., Mihatsch, W. y Polzin-Haumann, C. (2012): Variación diatópica, normas pluricéntricas y el ideal de una norma panhispánica”. En Lebsanft, F. Mihatsch, W. y C. Polzin-Haumann, C. (eds.): El español, ¿desde las variedades a la lengua pluricéntrica? Madrid, Iberoamerica Veruert, págs. 7-18.

López Morales, H. (2006). La globalización del léxico hispánico. Madrid, Espasa.

Ministerio de Turismo. Presidencia de la Nación (2013): Tesauro turístico argentino. www. cienaniosdeturismo.gov.ar (05-11-2012)

Moreno, F. (1999: "Lenguas de especialidad y variación lingüística”. En Barrueco, S. Hernández, E. y L. Sierra (eds.): Lenguas para fines específicos (VI). Investigación y enseñanza. Alcalá de Henares. Universidad de Alcalá, págs. 3-14.

Real Academia Española (2014): Diccionario de la lengua española. Madrid, Espasa. 
Regueiro, M.L. (2010): La sinonimia. Madrid, Arco Libro.

Sánchez Manzanares, C. (2013): "Valor neológico y criterios lexicográficos para la sanción y censura de neologismos en el diccionario general", Sintagma, 25, págs. 11-125.

Sanmartín, J. (2011): "Unidad y variación en el español del turismo: las páginas web de promoción de hoteles de España y Chile". En Calvi, M.V. y G. Mapellli (eds.): La lengua del turismo. Géneros discursivos y terminología. Bern, Peter Lang, págs. 335-358.

Sanmartín, J. (2012): "De las normativas turísticas a las páginas electrónicas de promoción de hoteles: la clasificación hotelera desde la perspectiva lingüística". En J. Sanmartín (ed.), Discurso turístico e Internet. Madrid, Iberoamericana, págs. 81-124.

SERNATUR (2008): Glosario de Turismo, Boletín Técnico Nº1/2008, SERNATUR, Departamento de Planificación. [PDF]

Seghezzi, N. (2013): "Variación terminológica: de la escritura a la oralidad", Debate Terminológico, 9 , págs. $62-80$.

Tebé, C. y Azarian, J. (2011): "Elaboración de definiciones terminológicas en normas UNE”, Debate Terminológico, 7 , págs. 2-23.

Temmerman, R. (2001): "Sociocognitive terminology theory". En Cabré, M.T. y J. Freixa (eds.): Terminología y cognición. Barcelona, IULA, págs. 75-92.

UNWTO (2010): Recomendaciones internacionales para estadisticas del turismo 2008, Serie M No83/Rev.1, Madrid-Nueva York: Publicación de las Naciones Unidas: http://unstats.un.org/unsd/ publication/SeriesM/Seriesm_83rev1s.pdf (05-11-2012)

UNWTO (2013): Panorama OMT del turismo internacional: http://www.iberglobal.com/files/turismo_ mundial.pdf (05-11-2012)

\section{Anexo I. Normas y legislación sectorial}

Internacionales: International Standard ISO 18513 Tourism services-Hotels and other types of tourism accommodation-Terminology.

Argentina: Ley Nacional de Hotelería 18828/70 y su Decreto Reglamentario 1818/76, 6-11-1970 / Decreto $N^{\circ} 1125$ (Salta), 14-8-1980, reformulado en 2011 / Decreto No 4764 (Salta), 8-11-2011 / Decreto No1359 (Córdoba), 5-9-2000 / Decreto No 659 (Buenos Aires), 24-4-2007 / Normas Argentinas IRAM SECTUR: 4225 / 42240 / 42210 / 42230 / 742200. 2010.

Chile: Normas Chilenas Oficiales: Clasificación, calificación y terminología de los establecimientos de alojamiento turístico Preámbulo NCh2760.Of2007-2013 / NCh2948.Of2012 / Nch2971.Of2006 / NCh2964.Of2013 / NCh3009-2012 / NCh3002.Of2007 / NCh2963.Of2006 / NCh2980-2012/ NCh2949.Of2005 / NCh2912-2012/NCh3285.Of2013 / NCh2964.Of2013 / NCh2939.Of2005 / NCh3027:2013. / Ley n. ${ }^{\circ} 20.423$ del Sistema Institucional para el desarrollo del turismo, Ministerio y Subsecretaría de Economía, Fomento y Reconstrucción, 2010 /

Costa Rica: Proyecto de Ley General del turismo, 2008 / Reglamento de las empresas de hospedaje turístico. Decretos Ejecutivos no 11217. 1980 / n 34717. 2008.

España: Ley 14/2008, de 3 de diciembre de turismo de Galicia. / AENOR (2004) UNE-EN ISO 1513 Servicios turísticos- Hoteles y otros tipos de alojamientos Terminolgía (ISO 18513:2003).

\section{Anexo II. Páginas web institucionales. Buscadores}

Sitio Web Oficial del Ministerio de Cultura y Turismo de la Provincia de Salta. http://turismo.salta.gov. ar (05-11-2012) / Servicio Nacional de turismo de Chile. SERNATUR http://www.sernatur.cl (05-112012)/ Costa Rica, Sin ingredientes Artificiales. Sitio oficial http://www.visitcostarica.com (05-11-2012) 